\title{
The impact of bridge pier on ice jam evolution - an experimental study
}

\author{
Jun Wang ${ }^{1}$, Jian Hua ${ }^{1}$, Jueyi Sui ${ }^{2 *}$, Peng $\mathrm{Wu}^{3}$, Tao Liu ${ }^{4}$, Pangpang Chen ${ }^{5}$ \\ ${ }^{1}$ School of Civil Engineering, Hefei University of Technology, 193 Tunxi Road, Hefei, Anhui, China. \\ 2 Environmental Engineering, University of Northern British Columbia, 3333 University Way, Prince George, BC, Canada. \\ ${ }^{3}$ Environmental Systems Engineering, University of Regina, 3737 Wascana Pkwy, Regina, SK, Canada. \\ ${ }^{4}$ China Water Northeastern Investigation, Design and Research Ltd., Changchun, China. \\ ${ }^{5}$ School of Civil Engineering, Hefei University of Technology, 193 Tunxi Road, Hefei, Anhui, China. \\ * Corresponding author. E-mail: jueyi.sui@unbc.ca
}

\begin{abstract}
The ice jam in a river can significantly change the flow field in winter and early spring. The presence of bridge piers further complicates the hydraulic process by interacting between the ice jam and bridge piers. Using the data collected from experiments in a laboratory flume, the evolution of an ice jam around bridge piers having three different diameters has been investigated in this study. Compared to results without-pier, it was found that the formation of an ice jam in the downstream of bridge pier is faster than that in the upstream. The thickness distribution of the ice jam shows clearly different characteristics in front and behind of bridge piers at different stages of the ice jam.
\end{abstract}

Keywords: Boundary condition; Bridge pier; Ice jam; Ice accumulation.

\section{INTRODUCTION}

During a rigid winter or early spring, ice jam can be a common problem, which may result in flooding in the northern hemisphere. In the past few decades, various research work has been conducted to investigate the hydraulic process of an ice jam both in natural rivers and laboratory flumes. However, most of this research was conducted without considering the impacts of bridge piers. For example, Sun et al. (1990) studied the ice jam evolution at the Hequ Reach of the Yellow River. Healy and Hicks $(2006,2007)$ simulated the ice jam accumulation process with steady and unsteady flow. It was found that the ice jam thickness is thinner under unsteady flow. But it can still apply to the ice thickness calculation under steady flow conditions. Sui et al. $(2002,2005,2008)$ studied the thickness distribution of ice accumulations along a bend channel based on field observations and experimental studies. Wang et al. (2007, 2011) looked at the evolution of ice jam by using $\mathrm{S}$ and $\mathrm{U}$ shape flumes. The sequence of ice jam accumulation and critical Froude number Fr was discussed. Based on experiments carried out in laboratory, Wang et al. (2015) studied the impacts of bridge piers on initiation of ice jams. Ambtman and Hicks (2012) developed a relationship between ice jam and discharge.

Based on field measurements, Beltaos and Burrell (2005, $2006,2010)$ analyzed the variation process of water temperature and water level during the period of river breakup. It is shown that flow heat transfer rate was influenced by the maximum roughness and porosity of ice jams during the breakup periods. The results of prototype observation of Matapedia River case studies in 1994 and 1995 were used to modify the ice jam simulation results and lay a foundation for the study on flow resistance characteristics. Through the theoretical analysis on internal strength properties of river ice jams, Beltaos (2010) pointed out some limitations of the constitutive equations and selections optimal parameters.

It should be noted that most of research work regarding river ice jam have been conducted without considering the presence of bridge piers. To date, very little literature can be found to investigate the impacts of bridge piers on the formation of ice jam. In fact, bridge piers and bridge abutments significantly change the flow boundary condition, which results in the changes in water level and flow velocity. Therefore, formation or initiation of ice jams in front of bridge piers/abutments is different. Based on experimental study in a laboratory flume, this study focuses on the following objectives: The impacts of bridge pier on ice jam accumulation. Critical conditions for the formation of an ice jam upstream of bridge pier. The impacts of bridge pier on the thickness of an ice jam around bridge pier.

\section{EXPERIMENT SETUP}

The present research has been conducted in the river ice hydraulic laboratory at Hefei University of Technology, China. As shown in Figure 1, the flume has a length of $26.68 \mathrm{~m}$ and width of $0.4 \mathrm{~m}$. In this experimental study, 22 cross sections were setup with a space-distance of $1.2 \mathrm{~m}$ from each other. Ice cubes were added at cross section 4 . In the downstream channel reach from cross section 20 to 22 , styrofoam was used to model ice cover. $3.5 \mathrm{~mm}$ spherical Polyethylene cubes were used to model ice cubes with a mass density of $0.918 \mathrm{~g} / \mathrm{cm}^{3}$, which are close to the mass density of natural ice $\left(0.917 \mathrm{~g} / \mathrm{cm}^{3}\right)$. Plastic cylinders were used to simulate bridge pier. The location of bridge pier was in the middle of the flume at cross section 16 .

So far, a lot of research work regarding local scour around bridge piers has been carried out. From numerical simulation and experimental study on local scour around a cylindrical pier conducted by Ling et al. (2007), Zhu et al. (2009), Wei et al. (2015) and Jiang (1994), the diameter of bridge pier and model dimensions are as follows: bridge pier diameter $d=15 \mathrm{~cm}$ (flume width $B=150 \mathrm{~cm}) ; d=5.08 \mathrm{~cm}(B=45.6 \mathrm{~cm}) ; d=8.9 \mathrm{~cm}$ $(B=122 \mathrm{~cm}) ; d=4 \mathrm{~cm}(B=100 \mathrm{~cm})$. One can see that the radio of $d / B$ researchers used is in the range of 0.04-0.11. According to the standard requirements of the People's Republic of China (JTG D60-2004), the bridge pier diameter should be less than $0.8 \mathrm{~m}$ when the bridge span is in the range of 5-20 m (namely, the span radio $d / B$ ranges from 0.04 to 0.16 ). Thus, in experimental study, three model bridge piers with different diameters of $2 \mathrm{~cm}, 3 \mathrm{~cm}$ and $4 \mathrm{~cm}$ were selected and located at cross section 16 . The ratio of $d / B$ is $0.05,0.075$ and 0.1 , respectively.

Cross section 4 was used as the control section. Before each experiment, the flow depth and mean flow velocity was measured and treated as initial flow depth $H_{0}$ and velocity $V_{0}$. Ice cube 


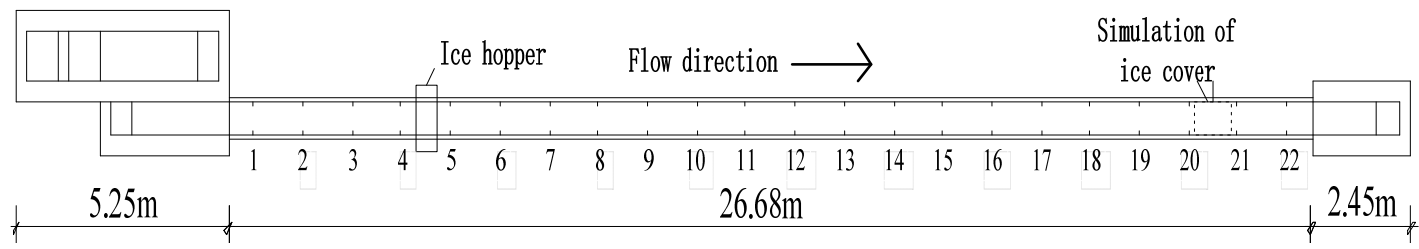

Fig. 1. Experimental set up.

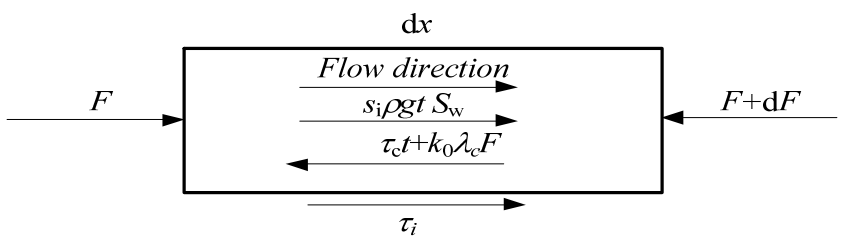

Fig. 2. Stress analysis of ice cube unit without bridge pier.

discharge was controlled by the ice hopper (for discharging ice cubes into the flume) as shown in Figure 1. The ice jam thickness $D_{i}$, and water depth under ice jam $h_{i}$ were measured along the flume section from cross section 5 to cross section 20 . Table 1 gives the flow conditions for all experiments conducted.

\section{CONTROL EQUATIONS FOR EQUILIBRIUM ICE JAM}

Following by the analysis conducted by Kenedy (1962), the stress analysis of an ice jam element (without bridge pier) is shown in Figure 2. The force balance for an ice jam element of an equilibrium state can be expressed as the following equation.

$$
B d F+2\left(\tau_{c} t+\lambda_{c} k_{0} F\right) d x=\left(\tau_{i}+s_{i} \rho g t S_{w}\right) B d x
$$

where, $s_{i}$ is the specific gravity of ice; $t$ is the thickness of ice jam; $\rho$ is the mass density of water; $S_{w}$ is the hydraulic slope, $k_{0}$ is the transverse thrust coefficient; $g$ is the gravitational acceleration; $\tau_{i}$ is the drag force on ice jam bottom surface; $B$ is the ice jam width which equals to river width in this case; $F$ is the internal force acting on an unit length of the ice jam; $\lambda_{C}$ is the internal friction coefficient; $\tau_{c}$ is the internal cohesive force of the ice jam.

It is assumed that the hydraulic pressure force in the ice jam toe is $f_{1}$. Equation (1) can be integrated to get Equation (2), which is also the modified Kennedy Equation from Pariset et al. (1966).

$$
\begin{aligned}
& F=\frac{B}{2 k_{0} \lambda_{c}}\left(\tau_{i}+s_{i} \rho g t S_{w}\right)-\frac{\tau_{c} t}{k_{0} \lambda_{c}} \\
& -\left\{\frac{B}{2 k_{0} \lambda_{c}}\left(\tau_{i}+s_{i} \rho g t S_{w}\right)-\frac{\tau_{c} t}{k_{0} \lambda_{c}}-f_{1}\right\} \exp \left[\frac{-2 k_{0} \lambda_{c} x}{B}\right] \\
& \text { In Equation (2), if } \frac{B}{2 k_{0} \lambda_{c}}\left(\tau_{i}+s_{i} \rho g t S_{w}\right)-\frac{\tau_{c} t}{k_{0} \lambda_{c}}-f_{1}<0,
\end{aligned}
$$

the $F$ can reach its maximum value at the ice jam toe and the value of $F$ is decreasing along the downstream direction which is called narrow channel jam; if

$\frac{B}{2 k_{0} \lambda_{c}}\left(\tau_{i}+s_{i} \rho g t S_{w}\right)-\frac{\tau_{c} t}{k_{0} \lambda_{c}}-f_{1}>0$, the value of $F$ is in-
Table 1. Experimental conditions.

\begin{tabular}{ccccc}
\hline$d(\mathrm{~cm})$ & $H_{0}(\mathrm{~cm})$ & $V_{0}(\mathrm{~m} / \mathrm{s})$ & $\mathrm{Fr}$ & $Q_{i}(\mathrm{~L} / \mathrm{s})$ \\
\hline 2 & 10 & 0.13 & 0.131482 & 0.011618 \\
2 & 10 & 0.14 & 0.141563 & 0.012850 \\
2 & 10 & 0.15 & 0.151422 & 0.021616 \\
2 & 10 & 0.16 & 0.161683 & 0.012530 \\
2 & 10 & 0.17 & 0.172349 & 0.012480 \\
2 & 10 & 0.175 & 0.176731 & 0.013020 \\
2 & 10 & 0.18 & 0.181926 & 0.011800 \\
2 & 15 & 0.14 & 0.115471 & 0.011465 \\
2 & 15 & 0.15 & 0.123700 & 0.011508 \\
2 & 15 & 0.16 & 0.131995 & 0.014286 \\
2 & 15 & 0.17 & 0.140381 & 0.011800 \\
2 & 15 & 0.18 & 0.148559 & 0.012550 \\
2 & 15 & 0.19 & 0.157016 & 0.012271 \\
2 & 20 & 0.15 & 0.107301 & 0.010447 \\
2 & 20 & 0.16 & 0.114456 & 0.012233 \\
2 & 20 & 0.17 & 0.121502 & 0.010375 \\
2 & 20 & 0.18 & 0.128601 & 0.009831 \\
2 & 25 & 0.18 & 0.115080 & 0.010633 \\
2 & 25 & 0.185 & 0.118224 & 0.009336 \\
2 & 25 & 0.19 & 0.121418 & 0.011949 \\
3 & 10 & 0.13 & 0.131482 & 0.009727 \\
3 & 10 & 0.14 & 0.141563 & 0.010920 \\
3 & 10 & 0.14 & 0.141563 & 0.011080 \\
3 & 10 & 0.15 & 0.151422 & 0.010269 \\
3 & 10 & 0.15 & 0.151422 & 0.009580 \\
3 & 15 & 0.13 & 0.107167 & 0.010674 \\
3 & 15 & 0.15 & 0.123684 & 0.010763 \\
3 & 15 & 0.16 & 0.131995 & 0.011532 \\
3 & 15 & 0.17 & 0.140381 & 0.011203 \\
3 & 20 & 0.15 & 0.107301 & 0.010924 \\
3 & 20 & 0.16 & 0.114456 & 0.010540 \\
3 & 20 & 0.17 & 0.121502 & 0.010619 \\
4 & 10 & 0.13 & 0.131482 & 0.009898 \\
4 & 10 & 0.14 & 0.141563 & 0.011700 \\
4 & 10 & 0.15 & 0.151422 & 0.009532 \\
4 & 10 & 0.16 & 0.161683 & 0.010300 \\
4 & 10 & 0.17 & 0.172349 & 0.009988 \\
4 & 15 & 0.14 & 0.115471 & 0.010870 \\
4 & 15 & 0.15 & 0.123700 & 0.011569 \\
4 & 15 & 0.16 & 0.131995 & 0.009634 \\
4 & 15 & 0.16 & 0.131995 & 0.012271 \\
4 & 15 & 0.165 & 0.136149 & 0.009216 \\
4 & 15 & 0.17 & 0.140381 & 0.009757 \\
4 & 20 & 0.15 & 0.107301 & 0.010320 \\
& 20 & 0.16 & 0.114456 & 0.008667 \\
& 20 & 0.17 & 0.121502 & 0.009389 \\
4 & 25 & 0.17 & 0.108627 & 0.009529 \\
\hline & & & & \\
4 & 10 &
\end{tabular}


creasing in the downstream direction and it can reach the maximum at the tail section of ice jam, which is called wide channel jam. The mechanical analysis is also suitable for the first condition of the ice jam evolution (see section 4.1a).

With the presence of bridge pier, the forces acting on ice jam in front of the pier includes drag force on ice jam bottom caused by flowing water, gravity force component in the flow direction, supporting force caused by river bank and pier, friction forces between pier and ice jam as well as the cohesive force, as shown in Figure 3. Therefore, the force balance equation can be given as following:

$$
\begin{aligned}
& B d F+\left[2\left(\tau_{c} t+\lambda_{c} k_{0} F\right)+2 n\left(\tau_{p} t+\lambda_{p} k_{0} F\right)\right] d x \\
& =\left(\tau_{i}+s_{i} \rho g t S_{w}\right) B d x
\end{aligned}
$$

where $n$ is the number of bridge piers; $\lambda_{p}$ is the internal friction coefficient between ice jam and bridge pier; $\tau_{p}$ is the cohesive force between ice jam and bridge pier.

According to the American Association of State Highway and Transportation Officials (ASSHTO, 2004), the forces acting on bridge pier by ice load can be calculated by:

$$
\begin{aligned}
& F_{p}=\min \left(C_{a} p t w, C_{n} p t^{2}\right), \frac{w}{t} \leq 6.0 \\
& F_{p}=C_{a} p t w, \frac{w}{t}>6.0 \\
& C_{a}=(5 t / w+1)^{0.5} \\
& C_{n}=\frac{0.5}{\tan (\alpha-15)}
\end{aligned}
$$

where, $t$ is the thickness of ice jam (mm); $\alpha$ is the angle between pier surface and ice cover which should larger than $15^{\circ}$; $p$ is the effective pressure $(\mathrm{MPa}) ; w$ is the interaction area of front pier surface with ice; Regarding the pressure on bridge piers caused by ice jam, AASHTO (2004) suggests that the range should be between $0.96 \times 10^{-3}$ and $9.6 \times 10^{-3} \mathrm{MPa}$, while the Canadian Highway Bridge Design Code (CSA, 2000) suggests a range from $5 \times 10^{-3}$ to $10 \times 10^{-3} \mathrm{MPa}$.

If the location of the front surface of pier is defined as $x=x_{0}$, Equation (2) can be modified as the following to determine the force per unit width acting on the front face of bridge pier:

$$
\begin{aligned}
& f_{2}=\frac{B\left(\tau_{i}+s_{i} \rho g t S_{w}\right)}{2 k_{0} \lambda_{c}}-\frac{\tau_{c} t}{k_{0} \lambda_{c}} \\
& -\left\{\frac{B\left(\tau_{i}+s_{i} \rho g t S_{w}\right)}{2 k_{0} \lambda_{c}}-\frac{\tau_{c} t}{k_{0} \lambda_{c}}-f_{1}\right\} \exp \left[\frac{-2 k_{0} \lambda_{c} x_{0}}{B}\right]-\frac{n F_{p}}{B}
\end{aligned}
$$

Meanwhile, Equation (3) is integrated, with the initial conditions of $x=x_{0}, F=f_{2}$, then Equation (9) can be acquired.

$$
\begin{aligned}
& F=\frac{B\left(\tau_{i}+s_{i} \rho g t S_{w}\right)}{2\left(\lambda_{c}+n \lambda_{p}\right) k_{0}}-\frac{\tau_{c}+n \tau_{p}}{k_{0}\left(\lambda_{c}+n \lambda_{p}\right)} t \\
& -\left\{\begin{array}{c}
\frac{B\left(\tau_{i}+s_{i} \rho g t S_{w}\right)}{2 k_{0}\left(\lambda_{c}+n \lambda_{p}\right)}- \\
\frac{\tau_{c}+n \tau_{p}}{k_{0}\left(\lambda_{c}+n \lambda_{p}\right)} t-f_{2}
\end{array}\right\} \exp \left[\frac{-2}{B} k_{0}\left(\lambda_{c}+n \lambda_{p}\right)\left(x-x_{0}\right)\right]
\end{aligned}
$$

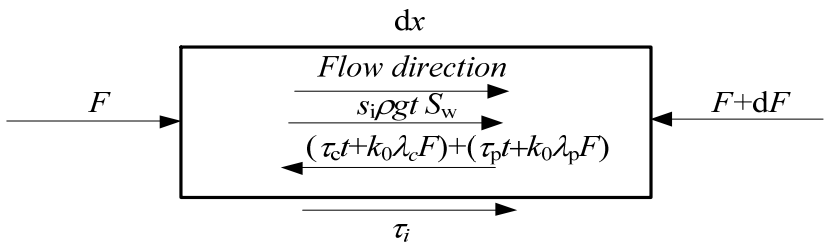

Fig. 3. Stress analysis of ice cube unit considering impacts of pier.

It is clear that $0 \leq x-x_{0} \leq l$, in which, $l$ is the thickness (or diameter) of pier in the flow direction.

It can be seen that from the expression that, with the presence of bridge pier, the supporting force from the bridge pier is increased while the internal force of ice jam is decreased. If $x-x_{0}=l$, then, the internal forces of ice jam at the rear surface of bridge pier can be derived as Equation (10).

$$
\begin{aligned}
& f_{3}=\frac{B\left(\tau_{i}+s_{i} \rho g t S_{w}\right)}{2\left(\lambda_{c}+n \lambda_{p}\right) k_{0}}-\frac{\tau_{c}+n \tau_{p}}{k_{0}\left(\lambda_{c}+n \lambda_{p}\right)} t \\
& -\left\{\begin{array}{c}
\frac{B\left(\tau_{i}+s_{i} \rho g t S_{w}\right)}{2 k_{0}\left(\lambda_{c}+n \lambda_{p}\right)}- \\
\frac{\tau_{c}+n \tau_{p}}{k_{0}\left(\lambda_{c}+n \lambda_{p}\right)} t-f_{2}
\end{array}\right\} \exp \left[\frac{-2}{B} k_{0}\left(\lambda_{c}+n \lambda_{p}\right) l\right]
\end{aligned}
$$

when equilibrium ice jam toe is located in the downstream of the pier, it could be assumed that $F_{p}=0$. The friction force between ice jam and bridge pier $k_{0} \lambda_{\mathrm{p}} F$ can be neglected comparing to the increase in drag force on ice jam bottom surface due to the piers which resulted in the decrease in channel width. Hence, the reasons lead to the second condition of the ice jam evolution can be found from Equation (9). Firstly, the mechanical characteristics around the bridge pier allow a decrease in equilibrium ice jam thickness. Secondly, the ability of ice transportation has been more or less increase due to the significantly change of flow filed around the piers (Section 4.1b).

When ice cubes transported around piers is more than the incoming ice discharge $Q_{i}$, ice jam cannot be developed in channel upstream of the bridge pier. However, ice jam can be formed in the channel downstream of pier. The evolution process of ice jam is similar to that from the first condition. As mentioned above, this is considered as the third condition for development of ice jam (see Section 4.1c).

\section{RESULTS AND ANALYSIS}

It was observed that the flow field around bridge pier was dramatically changed due to the presence of bridge pier. Also, there was scouring phenomenon of ice cubes around bridge pier which was similar to the river-bed local scour process around bridge pier. Based on experiments, following findings were noticed:

a) Due to the presence of horseshoe vortex around bridge pier, ice cubes move faster than that without bridge pier. If ice cubes in front of ice jam have a larger velocity than critical submergence velocity, ice cubes will be submerged under ice jam around the pier, as shown in Figure 4. It can be seen that, at the beginning of each experiment, for certain distance away from the bridge piers, there is no ice cube submerged. Ice jam will be gradually formed on water surface before approaching bridge pier. The closer to the pier, the more ice cubes were submerged into water due to the horseshoe vortex around 


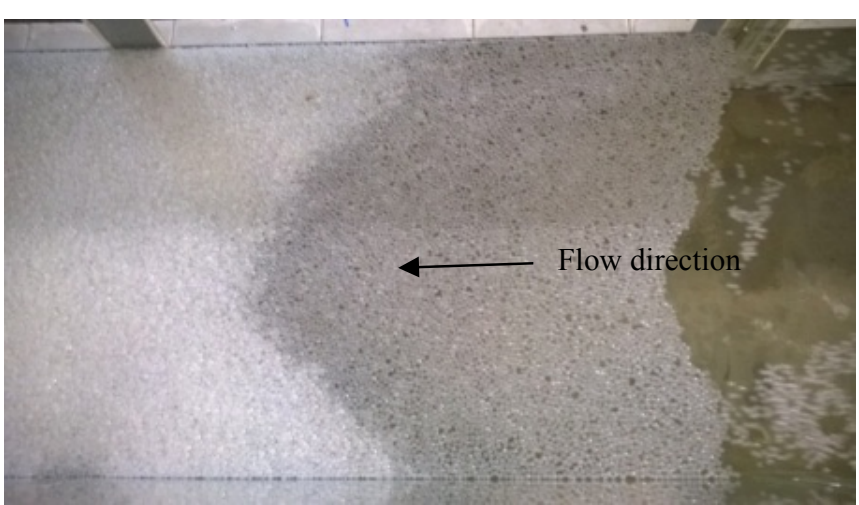

(a) Ice jam front line at the beginning.

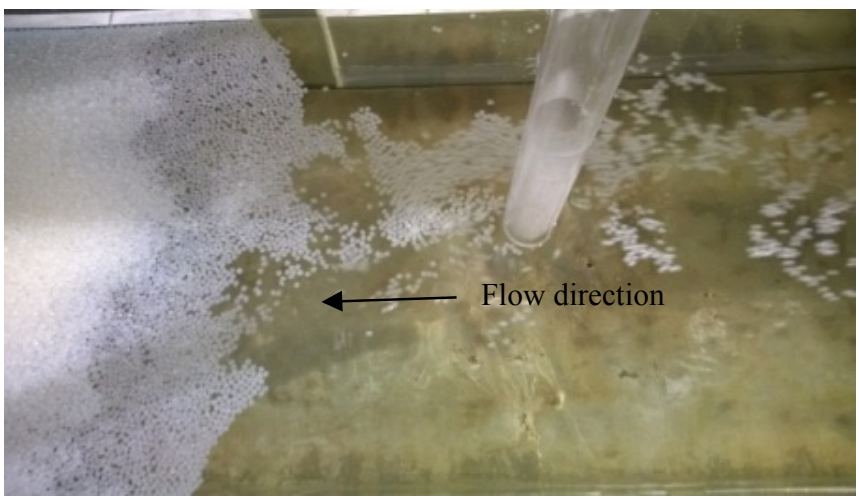

(b) Ice jam front line near bridge pier.

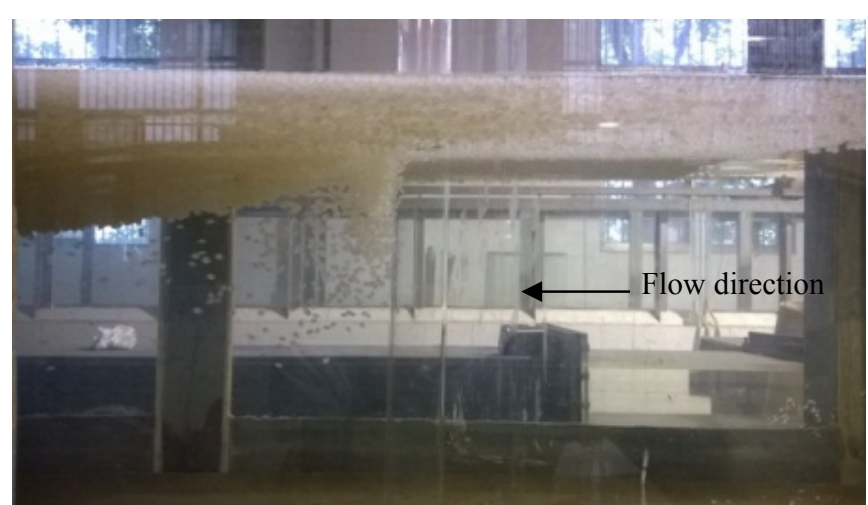

Fig. 5. Local scour of ice jam caused by the thickening process of ice jam around the pier.

bridge pier. As shown in Figure 6, the closer to the pier, the thinner to the ice jam.

b) When the ice jam reaches the upstream of bridge pier, ice cubes around the pier moves faster to the downstream, and then accumulation in the downstream of bridge pier happened. At the beginning of each experiment, the ice cube congested downstream of the pier. With the increase in the accumulation body, cross section under ice jam deceased and the flow velocity increased. Thus, ice cubes started to progress further downstream. It have been noticed that, the ice jam accumulation downstream of bridge pier is the thickest in the middle of ice jam, and becomes thinner further downstream, as shown in Figure 5.

Fig. 4. Ice jam front line at different locations.
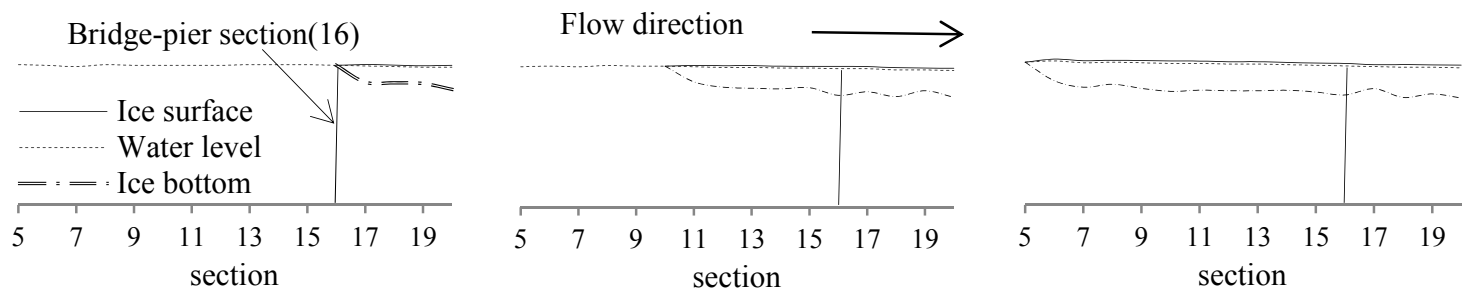

(a) $d=2 \mathrm{~cm}, V_{0}=0.13 \mathrm{~m} / \mathrm{s}, H_{0}=10 \mathrm{~cm}, Q_{i}=0.012 \mathrm{~L} / \mathrm{s}$
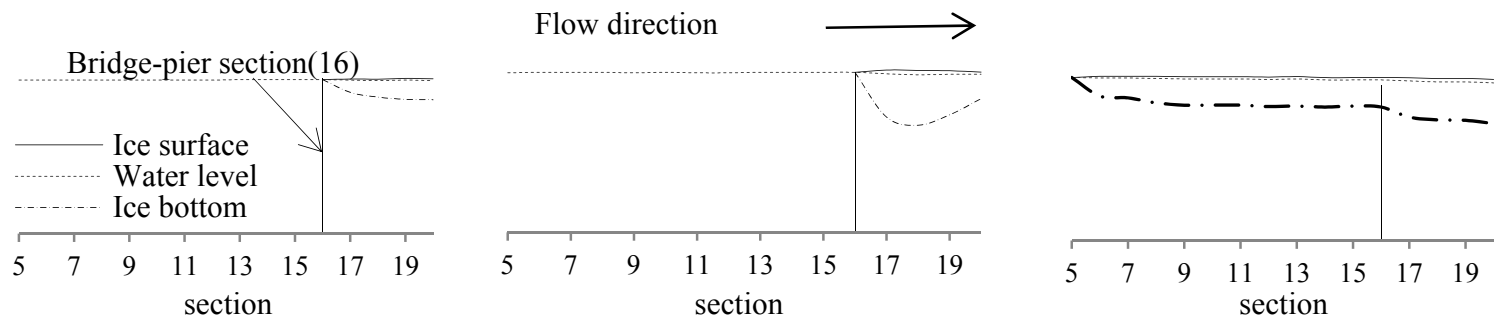

(b) $d=4 \mathrm{~cm}, V_{0}=0.16 \mathrm{~m} / \mathrm{s}, H_{0}=15 \mathrm{~cm}, Q_{i}=0.010 \mathrm{~L} / \mathrm{s}$
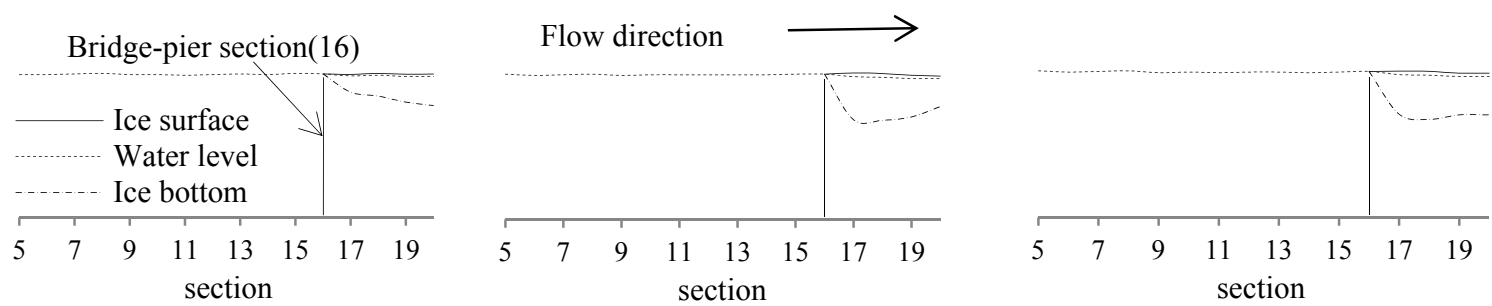

(c) $d=4 \mathrm{~cm}, V_{0}=0.16 \mathrm{~m} / \mathrm{s}, H_{0}=10 \mathrm{~cm}, Q_{i}=0.010 \mathrm{~L} / \mathrm{s}$

Fig. 6. The ice jam evolution around the pier. 


\section{Effect of bridge pier on ice jam thickness}

Experiment shows, the thickness of ice jam was dependent on the flow conditions, ice discharge and pier diameter. Based on our experiments, following three conditions for the development of an ice jam can be summarized:

a) when the Froude number is low and ice discharge is large with small pier diameter, the evolution of ice jam is similar to that without bridge pier, as shown in Figure 6a;

b) when the Froude number is high and pier diameter is large, the accumulation of ice jam around the pier is different. When ice cubes reach the front of the pier, due to the acceleration in the section, more ice cubes are submerged into the water. During the process of ice jam formation in the upstream section of bridge pier, the ice jam thickness in the downstream section of the pier is firstly increased, then the ice jam thickness in the upstream section starts to become larger, as shown in Figure 6b;

c) with the increase in the Froude number and pier diameter, the acceleration around piers increases. If the ice discharge from upstream is less than that moving into the water, no ice jam can be developed in the upstream section of the pier, as shown in Figure 6c.

\section{Critical conditions for formation of ice jam upstream of bridge pier}

Whether or not an ice jam can be initiated upstream of the bridge pier depends not only on the pier size, but also on hydraulic factors such as Froude number. Based on analysis of data collected regarding the formation of ice jam upstream of pier, it was found that under different pier diameters, the critical condition was determined by the ratio of Froude number and ice discharge, $\mathrm{Fr} / Q_{i}$. If $\mathrm{Fr} / Q_{i}$ was between 0.10 and 0.18 , a linear relationship can be found, as shown in Figure 7. Due to the presence of bridge pier, the flow field was significantly changed. A lot of ice cubes were submerged or trapped (by flow) into the water. If the amount of ice cube submerging into the water was more than that of coming from upstream, ice jam cannot be progressed to the upstream region of bridge pier. Namely, under the same flow conditions, to initiate an ice jam around the pier, more ice discharge in the channel is needed, as shown in Figure 7.

\section{The impacts of bridge pier on ice jam thickness}

The presence of bridge pier has significant impact on the thickness distribution of ice jam in both upstream and down-

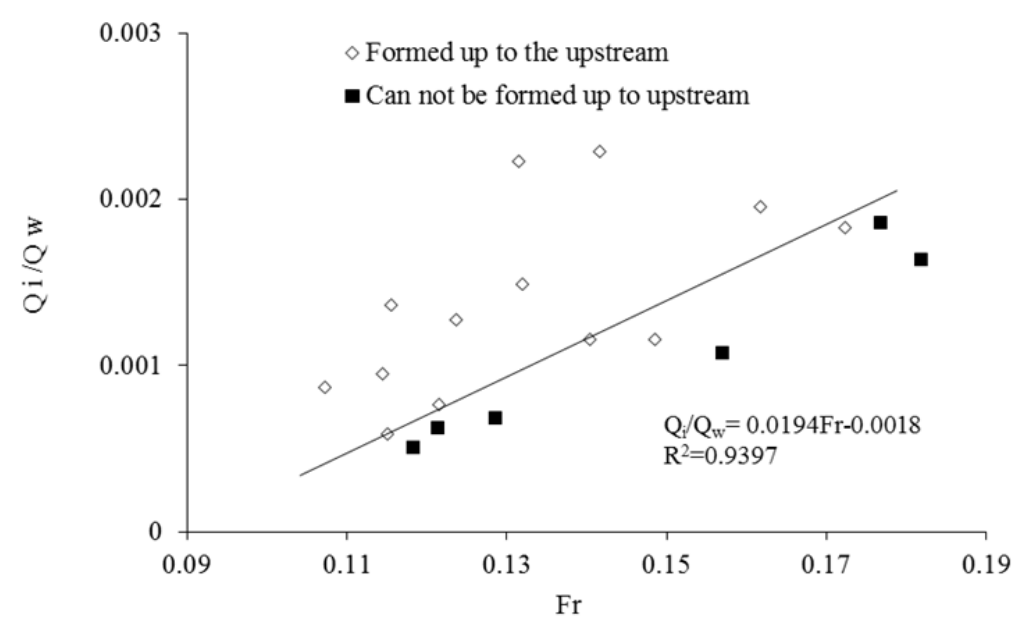

(a) $d=2 \mathrm{~cm}$

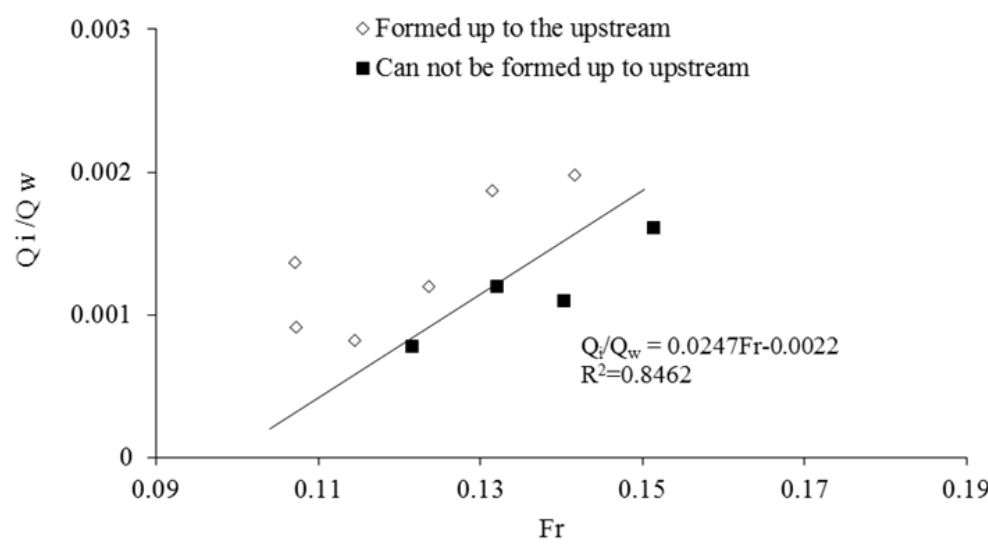

(b) $d=3 \mathrm{~cm}$ 


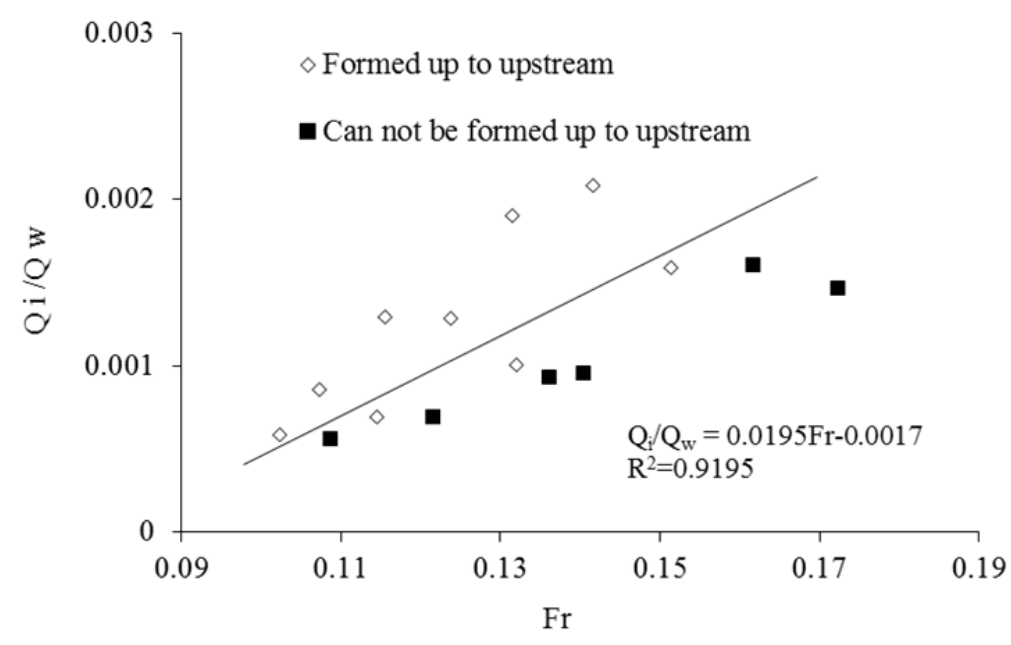

(c) $d=4 \mathrm{~cm}$

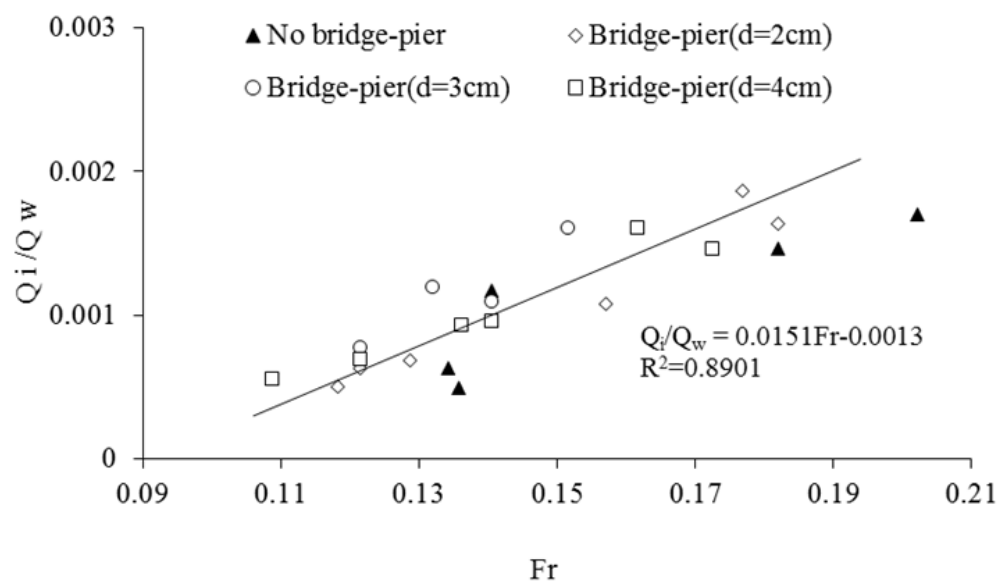

(d) The critical condition for ice jam formation for different pier-conditions

Fig. 7. The critical condition for ice jam formation in the upstream.

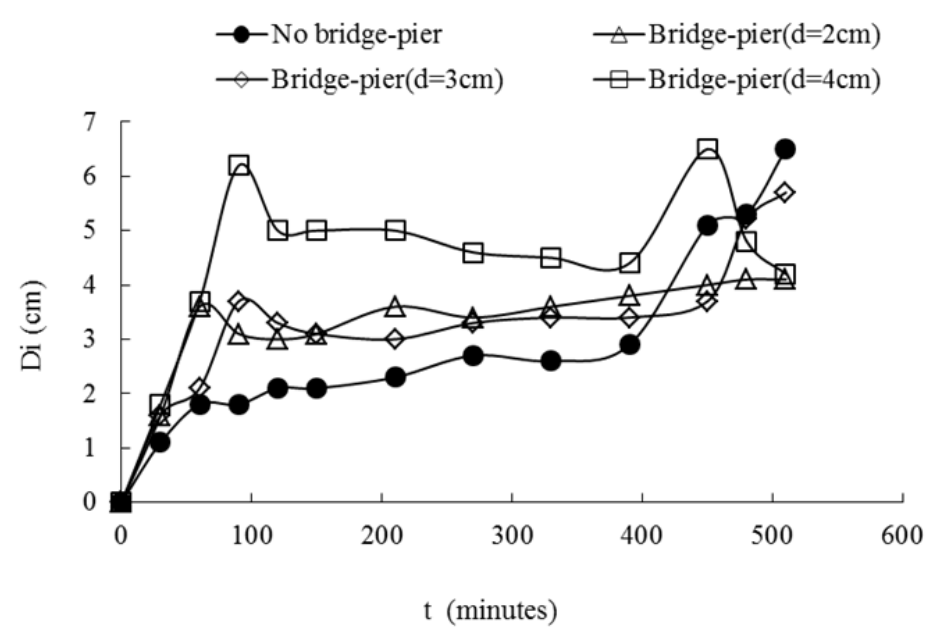

Fig. 8. Variation in ice jam thickness at cross section 18.

stream channel. Cross section 18 was used as an example to show the difference, as shown in Figure 8. It should be noted that, the flow conditions for Figure 8: flow depth is $15 \mathrm{~cm}$, approaching mean flow velocity is $0.15 \mathrm{~m} / \mathrm{s}$ and ice discharge is
$0.01 \mathrm{~L} / \mathrm{s}$. Comparing to the variation in ice jam thickness without bridge pier, it can be found that the ice jam thickness around piers is significantly increased at the beginning. After passing the pier, the thickness is decreased before reaching a 
constant value. During the first 2 hours of experiment, the ice jam reaches the largest thickness. When the pier diameter is $4 \mathrm{~cm}$, the ice jam thickness has the maximum value of $6.2 \mathrm{~cm}$, which is equal to the final equilibrium thickness of ice jam. For a smaller pier diameter of $d=2 \mathrm{~cm}$, the maximum thickness of ice jam is $3.7 \mathrm{~cm}$, which is less than the equilibrium ice jam thickness. However, the maximum thickness of ice jam without bridge pier is just about $2 \mathrm{~cm}$, which is much less than the thickness when the bridge pier is presence in the channel. This is due to the presence of bridge pier which increases the ability of ice transportation at the bridge pier section. Some ice cubes can be delivered to downstream of bridge piers, thus ice jam thickness along the downstream section increased first. Then the upstream water stage is increased. As a result, the ability of ice transportation around piers was reduced. Finally the ice jam toe of the upstream ice jam gradually approaches close to bridge pier.

Figure 9 is introduced to show the variation in ice jam thickness at cross section 11 , which has the flow depth of $15 \mathrm{~cm}$, mean flow velocity of $0.15 \mathrm{~m} / \mathrm{s}$ and ice discharge of $0.01 \mathrm{~L} / \mathrm{s}$. It is interesting to note that the thickness of ice jam has a similar trend to that without the presence of pier in the channel. However, it took longer time for the ice jam toe to develop around piers, as shown in the figure.

Figure 10 shows dependence of the ratio of existing time of ice jam around pier to equilibrium time $\left(T_{i} / T\right)$ on Froude number, ice discharge over water discharge $\left(Q_{i} / Q_{w}\right)$. Different pier diameters and blockage ratio are presented in the figure. The existing time of ice jam around the pier is affected by Froude Number, ice discharge and flow discharge, as well as pier diameter. With the increased in Froude Number, the time ratio $T_{i} / T$ increases correspondingly. In contrast, $T_{i} / T$ decreases with an increase in $Q_{i} / Q_{w}$. One can also see that $T_{i} / T$ increase together with an increase in pier diameter and $d / B$.

\section{CONCLUSIONS}

The ice jam evolution around bridge pier is investigated based on experimental study by using three pier diameters. The following findings have been drawn from this research.

(1) Due to the presence of bridge pier, the flow field was significantly changed. More ice cubes have been noticed to submerge into the water. When the Froude number is small and ice discharge is large with small pier diameter, the evolution of ice jam is similar to that without presence of a bridge pier. When the Froude number and pier diameter is large, during the process of ice jam formation in the upstream of the bridge pier, the ice jam thickness in the downstream of the pier is firstly increased, then the ice jam thickness in the upstream of the pier starts to become larger. With the increase in Froude number and pier diameter, if the ice discharge from upstream is less than that submerged into the water, ice jam cannot be initiated in the upstream of the pier. It means, under the same flow conditions, formation of ice jam around the pier needs more ice discharge.

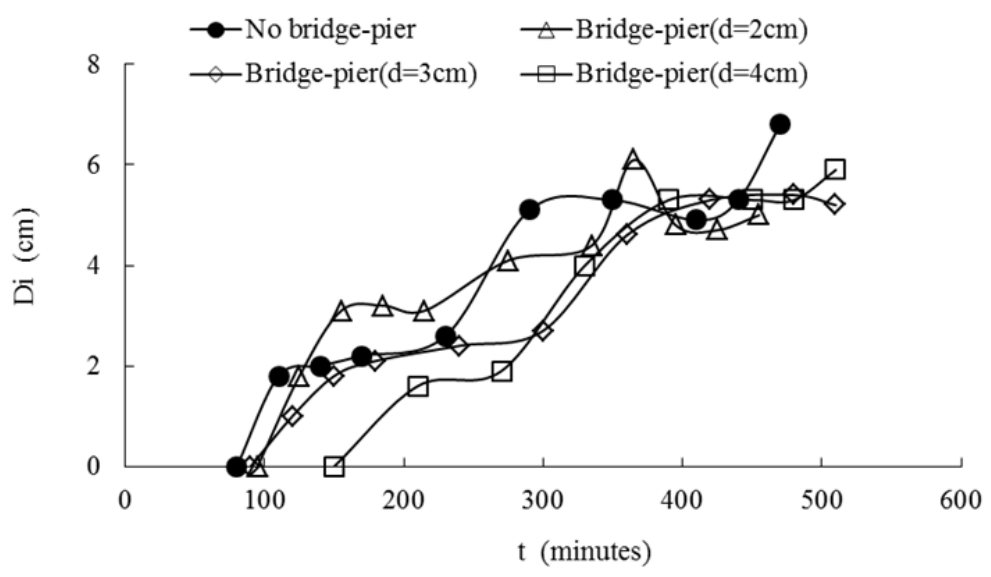

Fig. 9. Variation in ice jam thickness at cross section 11.

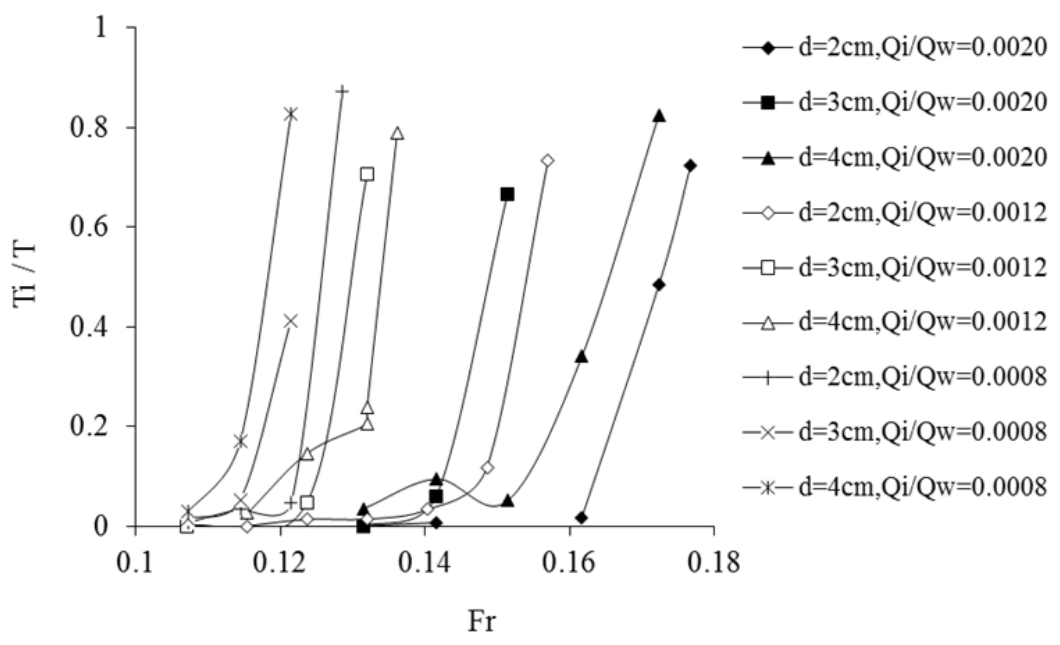

Fig. 10. The variation of existing time of ice jam around pier with pier conditions. 
(2) If the bridge pier diameter is the same, the critical condition for formation of an ice jam around bridge pier was determined by the Froude number and ice discharge. It is also found that if the Froude Number is between 0.1 and 0.18 , there is a linear relationship to determine if the ice jam can happen in the upstream channel of the bridge pier.

(3) Comparing to the ice jam variation without presence of a bridge pier, it is found that the thickness of ice jam around piers is significantly increased at the beginning. After passing the pier, the thickness is decreased before reaching a constant value. For the section upstream of pier, it is interesting to note that the thickness of ice jam has a similar trend to that without any pier presence in channel. However, the formation of ice jam toe around piers took longer time to get develop than that without bridge pier; the existing time of ice jam around the pier is affected by Froude Number, ice discharge and flow discharge, as well as pier diameter. With the increased in Froude Number, the value of $T_{i} / T$ increases correspondingly. In contrast, $T_{i} / T$ decreases with an increase in $Q_{i} / Q_{w}$. It is also found that $T_{i} / T$ increase together with an increase in pier diameter and $d / B$

Acknowledgements. The present study is financially supported by the National Natural Science Foundation of China (Grant No.51379054). The authors are greatly thankful for the support.

\section{REFERENCES}

AASHTO, 2004. Bridge Design Manual-LRFD.

Ambtman, K., Hicks, F., 2012. Field estimates of discharge associated with ice jam formation and release events. Canadian Water Resources Journal, 37, 1, 47-56.

Beltaos, S., 2010. Internal strength properties of river ice jams. Cold Regions Science and Technology, 62, 2, 83-91.

Beltaos, S., Burrell, B.C., 2005. Field measurements of ice-jamrelease surges. Canadian Journal of Civil Engineering, 32, 4, 699-711.

Beltaos, S., Burrell, B.C., 2006. Water temperature decay under breakup ice jams. Cold Regions Science and Technology, $45,3,123-136$.

Beltaos, S., Burrell, B.C., 2010. Ice-jam model testing: Matapedia River case studies, 1994 and 1995. Cold Regions Science and Technology, 60, 1, 29-39.

CSA, 2000. The Canadian Highway Bridge Design Code.

Healy, D., Hicks, F., 2006. Experimental study of ice jam formation dynamics, ASCE Journal of Cold Regions Engineering, 20, 4, 117-139.

Healy, D., Hicks, F., 2007. Experimental study of ice jam thickening under dynamic flow conditions. ASCE Journal of Cold Regions Engineering, 21, 3, 72-91.

Industry standard of the People's Republic of China, 2004. JTG D60-2004: General Code for Design of Highway Bridges and Culverts. (In Chinese.)

Jiang, H., 1994. Experimental study of local scour protection on bridge pier. Highway, 8, 1-8. (In Chinese.)
Kennedy, R.J., 1962. The forces involved in pulpwood holding grounds. Pulp and Paper Research Institute of Canada.

Ling, J., Lin, X., Zhao, H., 2007. Analysis of three-dimensional flow field and local scour of riverbed around cylindrical pier. Journal of Tongji University (Nature Science), 35, 5, 582-586. (In Chinese.)

Pariset, E., Hausser, R., Gagnon, A., 1966. Formation of ice covers and ice jams in rivers. Journal of the Hydraulics Division, 92, 6, 1-24.

Sui, J., Karney, B., Sun, Z., Wang, D., 2002. Field investigation of frazil jam evolution - a case study. ASCE Journal of Hydraulic Engineering, 128, 781-787.

Sui, J., Karney, B., Fang, D., 2005. Variation in water level under ice-jammed condition - Field investigation and experimental study. Nordic Hydrology, 36, 1, 65-84.

Sui, J., Wang, J., Balachandar, R., Sun, Z., Wang, D., 2008. Accumulation of frazil ice along a river bend. Canadian Journal of Civil Engineering, 35, 158-169.

Sun, Z., Ni, J., Sui, J., 1990. Experimental studyof frazil ice jam formation and evolution process. Research Report, Hefei University of Technology, Hefei, China. (In Chinese.)

Wang, J., Gao, Y., Yin, Y., 2007. An experimental study of ice jam formation and its thickness distribution curved channel. Journal of Glaciology and Geocryology, 2, 5, 764-769. (In Chinese.)

Wang, J., Chen, P., Sui, J., 2011. Progress in studies on ice accumulation in river bends. Journal of Hydrodynamics, 23, $6,737-744$.

Wang, J., Shi, F., Chen, P., Wu, P., Sui, J., 2015. Impacts of bridge piers on the initiation of ice cover - an experimental study. Journal of Hydrology and Hydromechanics, 4, 327333.

Wei, Y., Ye, Y., Wu, K., 2015. 3D numerical modeling of flow and scour around a circular pile. The Ocean Engineering, 4, 65-70. (In Chinese.)

Zhu, Z., Liu, Z., Chen, Z., 2009. Three-dimensional numerical modeling of flow field and local scour around cylindrical pier. In: Proceedings of the 14th National Conference on Wind Engineering (Book 2). (In Chinese.)

\section{NOMENCLATURE}

$T: \quad$ ice jam stay time

$T_{i}$ : equilibrium time

$Q_{w}$ : water discharge

$Q_{i}$ : ice discharge

$H_{0}$ : initial flow depth

$V_{0}$ : initial velocity

$d$ : bridge pier diameter

$D$ : ice jam thickness
Received 14 October 2015 Accepted 11 December 2015

Note: Colour version of Figures can be found in the web version of this article. 